\title{
O CONCEITO DE MESSIANISMO NA OBRA DE WALTER BENJAMIN: DA LINGUAGEM PURA À HISTÓRIA UNIVERSAL
}

Maria João Cantinho

\begin{abstract}
RESUMO
Podemos afirmar com certeza que Walter Benjamin é um dos pensadores mais inclassificáveis do século XX. Isso não o torna menos importante, muito pelo contrário. A subtileza do seu pensamento obriga-nos a questionar as várias áreas do conhecimento, quer da filosofia, da crítica literária, da estética, da história, etc. E um dos conceitos nucleares da sua filosofia foi precisamente o do messianismo judaico. Porém, não podemos tomar o conceito, no seu sentido mais convencional, tal como ele é utilizado pela tradição mística judaica e pela teologia. Ao longo da sua vida e da sua obra, do campo da linguagem à tradução e à história, ele esteve presente, mas não da mesma forma, como procuraremos elucidar aqui. É preciso, também, compreender a função que o mesmo desempenhou no seu pensamento, abarcando os vários domínios do seu pensamento, desde a sua reflexão sobre a tradução às suas concepções sobre a linguagem e a história, ao arrepio das teorias convencionais. É disto que trataremos nesta conferência.
\end{abstract}

Palavras-chave: Messianismo. História. Linguagem. Tradução.

\section{THE MESSIANIC CONCEPT IN THE WORK OF WALTER BENJAMIN: FROM THE PURE LANGUAGE TO UNIVERSAL HISTORY}

\begin{abstract}
We can say that Walter Benjamim is one of the most unclassifiable thinkers of the twentieth century. That does not make him less important, on the contrary. The subtlety of his thinking compels us to question the various areas of knowledge like philosophy, literary criticism, aesthetics or history. And one of the core concepts of his philosophy was the Jewish messianism. But we can't take the concept in its most conventional sense, as it is used by the Jewish mystical tradition and theology. Throughout his life and his work, from the field of language to translation and history, he was present, but not in the same way, as we will try to elucidate here. It is also necessary to understand the role that it played in his thought, covering the various areas of his thinking, from its reflection on the translation to their conceptions of language and history, contrary to conventional theories. This is what this conference will deal.
\end{abstract}

Keywords: Messianism. History. Language. Translation.

Professora do Instituto de Arte, Design e Empresa (IADE - Lisboa). Doutora pela Universidade Nova de Lisboa. Portuguesa, residente em Lisboa - Portugal. Email: micantinho@gmail.com 
O mundo messiânico é o mundo da actualidade integral e, de todos os lados, aberta. Só nela existe a história universal. Mas não enquanto história escrita, mas sobretudo enquanto se cumpre como uma festa. Esta festa é purificada de toda a solenidade. Nenhuma espécie de canto a acompanha. A sua língua é uma prosa integral, que faz saltar as cadeias da escrita e é compreendida por todos os homens (como a língua dos pássaros por todas as crianças abençoadas aos domingos). - A ideia da prosa coincide com a ideia messiânica da história universal (as diferentes espécies de prosa artística formam o espectro do universal histórico (universalhistorische) - no Narrador).

Benjamin, Walter, Teses sobre o conceito de história, Ms. 470, p. 355.

A marginalidade do pensamento de Walter Benjamin inspira-nos e obriga-nos a questionar as várias áreas do conhecimento: a filosofia, a crítica literária, a estética, a história, a teoria da linguagem e a tradução. Leitor atento da história e da sua época, pode dizer-se que ele foi um sismógrafo da sua época, lendo e interpretando os sinais de uma modernidade contraditória que se desenhava ante si, sacudida pela evolução da técnica que transformou radicalmente o século XX. Foi, por outro lado, um ouvinte atento das vozes do passado e quis-se um guardião da herança histórica. Foi nesta contradição, ou melhor, nesta tensão que se moveu toda a complexidade do seu pensamento, a de um olhar visionário e de alguém que escuta os sinais do se tempo.

Por outro lado, tanto Bertold Brecht quanto Theodor Adorno o recriminavam, nas suas inúmeras cartas, pelas tendências benjaminianas para o messianismo judaico, esperando em vão que a "cura do materialismo dialéctico, a que havia sido convertido por Asja Lascis, tivesse expurgado aquilo que eles consideravam como um lado anacrónico do seu pensamento. Portanto, essa complexidade que nos encanta hoje, suscitou perplexidades nos homens do seu tempo. Era isso que Sholem, o seu melhor amigo, lamentava, ao escrever-Ihe, em tom de crítica, que ele poderia ter sido o maior "filósofo da linguagem" do seu tempo, se não tivesse cedido ao fascínio do materialismo dialéctico.

Um dos conceitos fundamentais do seu pensamento foi precisamente 0 do messianismo judaico. Porém, não podemos tomar o conceito, no seu sentido mais convencional, tal como ele é utilizado pela tradição mística judaica 
e pela teologia. Ao longo da sua vida e da sua obra, do campo da linguagem à tradução e à história, ele esteve presente, mas não da mesma forma, como procuraremos elucidar aqui. É preciso, também, compreender a função que o mesmo desempenhou no seu pensamento. Numa passagem da sua obra, Walter Benjamin reconheceu essa presença constante do messianismo judaico: "O meu pensamento comporta-se para com a teologia da mesma forma que o mata-borrão com a tinta. Ele fica totalmente embebido por ela. Mas se fosse seguir o mata-borrão, então nada subsistiria daquilo que está escrito" (BENJAMIN W. , Gesammelte Schriften I, 1972, 1235).

No meu trabalho de doutoramento, procurei fazer um mapeamento do modo como se desenvolve esse conceito na sua obra. $E$ encontrei essa preocupação logo no início da sua obra e de uma forma muito clara na sua correspondência de 1913 e 1914, ano em que se iniciou a Primeira Guerra Mundial. É precisamente em 1913, na sua correspondência com Carla Seligson, bem como nos textos de 1913 e 1914, respectivamente, como Der Moralunterrich, Die Religiöse Stellung der neuen Jugend, que o referido conceito se começa a definir no seu pensamento e se amplia a toda a sua obra. Nos escritos da sua juventude, Benjamin insiste na articulação entre a juventude, religião e comunidade, como uma tentativa de ultrapassar o misticismo individualista (BENJAMIN W. , 1974, 74). Por outro lado, o convívio intenso entre alunos e professores, sob a influência de Wynecken, o empenho no projecto pedagógico de uma "filosofia" da reforma, durante os anos que frequentou a faculdade, possibilitaram as condições para que ele defendesse com veemência o ideal da bela comunidade (schöne und freie Gemeinschaft). É, todavia, no artigo "A Vida dos Estudantes" que a comunidade - comunidade dos espíritos livres - que o conceito alcança a sua definição filosófica definitiva e inserida num horizonte mais vasto.

É na comunidade que Benjamin vê a possibilidade da origem de novas energias, de um novo futuro. A comunidade de que Benjamin fala define-se como "colectividade moral", como "sittliche Gemeinschaft" (BENJAMIN W. , 1974, 50). Desenvolvida quer por Wynecken, por Lietz e outros autores, pedagogos e filósofos, ela preconiza uma forma de elevação e/ou edificação comunitária. 
Uma ruptura profunda produz-se, assim, na geração mais jovem como a de Benjamin, sob a influência de Wynecken e da nova pedagogia. Dá-se uma radicalização da ética pura (a exigência de Absoluto de que Benjamin fala frequentemente na sua correspondência, com a possibilidade da sua aplicabilidade ao campo da história. Sem dúvida que o conceito de Gemeinschaft desempenha uma função crucial no debate filosófico dessa geração. Esta viragem que corresponde a uma mudança radical, que se escava e opõe a nova geração aos pedagogos e ao modelo então vigente, cederá o seu lugar, por sua vez, a um messianismo radical e a uma filosofia da história que exige uma forma de politização, que encontra a sua origem na utopia da comunidade e no activismo das vanguardas. Por outro lado, esta geração confronta-se com uma ameaça que é causada por uma crise do individualismo liberal, já visível no ensino dos mestres da sua época. É neste contexto, precisamente, que a categoria de comunidade aparece como um ponto de encontro ou de entrosamento; entre a ontologia e a ética pura, entre 0 sujeito singular em crise e o Sujeito messiânico, entre moral, pedagogia, religião e filosofia.

Ainda que seja um texto precoce, o texto "A Vida dos Estudantes", redigido em 1914, contém aspectos que já são emblemáticos do pensamento de Benjamin e que se desenvolverão a partir deste "encontro". Ele contém os elementos fundamentais da sua reflexão de juventude e são nele reconhecíveis esses elementos que constituem antecipações de conceitos, temas e problemas da sua filosofia da história. No centro dessa preocupação deparamo-nos com o conceito de Gemeinschaft. Aqui, o messianismo aloja-se na concepção de uma nova perspectiva crítica da história e que é a crítica ao progresso.

$\mathrm{Na}$ verdade, a crítica de Benjamin visa a evolução positivista das ciências, que desenvolvem, na sua especialização crescente, um aparelho burocrático e profissional sofisticado, em vez da "ideia do saber". A lógica do Beruf é o corolário daquele sistema e da especialização científica e, neste sentido, Benjamin propõe a definição da tarefa dos estudantes livres no sentido da comunidade, precisamente na contraposição da "vida profissional regenciada pelo Estado" (BENJAMIN W. , 1974, 77). O que é aqui proposto 
como base essencial é a ideia da restitutio in integrum, a procura do homem na sua "totalidade" (der ganze Mensch). Assim, opondo-se à Gesellschaft, a qual implica a divisão do saber e do trabalho, a Gemeinschaft orientar-se-á para a totalidade do homem agente (Ibidem).O modelo vigente é o do sujeito criador e todos aqueles que agem, de acordo com Benjamin, e que são movidos por uma aspiração à totalidade, recusando assim a alienação da essência humana. A sua crítica aproxima-se claramente de um certo tipo de Kulturkritik romântica. Ela reclama a ideia de salvação, no espírito de Tolstoi, entre as concepções anárquicas e as comunidades monásticas cristãs, na busca incessante de um ideal de vida espiritual e criadora, como um sopro renovador da ideia de cultura.

É precisamente desta época, certamente turbulenta e atravessada pelas grandes convulsões históricas, o início da Primeira Grande Guerra, as grandes inovações tecnológicas e o crepúsculo de toda uma cultura do progresso ligada ao século XIX, que data o interesse de Benjamin pela história. O colapso dos grandes ideais que haviam atravessado o século anterior desabaram sobre a barbárie da Primeira Grande Guerra, o mundo perdera o seu sentido, para estes jovens para quem o futuro Ihes aparecia sombrio e algo espectral.

Todas estas circunstâncias e condições determinaram uma crise no seio dos jovens intelectuais, à sua época. De França, os movimentos políticos que se encontravam ligados ao ideal de revolução e de anarquia inflamavam de esperança os jovens, que preferiam os movimentos revolucionários e românticos como inspiração viva. Daí, também, esta esperança no jovem Benjamin, a sua atracção pelo messianismo histórico, que era entendido como uma força transformadora e não uma categoria teológica abstracta. Michael Löwy (Löwy, Redenção e Utopia: o judaísmo libertário na Europa central, 1989), nas suas obras dedicadas aos temas do messianismo e da sua estreita relação aos movimentos revolucionário, diagnosticou com clareza a época.

As questões que referimos acima são pertinentes para delinear os pressupostos do messianismo benjaminiano. Se Benjamin pretendia, no início, seguir o pensamento de Wynecken, o mestre pedagogo que o fascinou, cedo compreendeu, no entanto, que se afastava dele em pontos fundamentais. Embora Wynecken fosse um idealista, foi também um positivista, seguindo 0 
espírito da sua época, radical e reformista. E Benjamin no seu activismo de juventude, também segue esta perspectiva da história de Wynecken, mas radicaliza-a no sentido de the conferir o elemento messiânico. Quanto ao outro vector da radicalização das perspectivas sobre a cultura e a história, Benjamin vai descobri-lo na segunda Consideração Intempestiva de Nietzsche (Nietzsche, 2011).

A crítica do historicismo do jovem Benjamin toma como alvo a herança da filosofia da história alemã, nomeadamente das perspectivas históricas do século XIX e, em particular, do hegelianismo, bem como do evolucionismo e do relativismo histórico que dominam o panorama do conhecimento histórico. Aquilo que Benjamin ataca é a história positivista, como ciência dos factos ou mecanismo de encadeamento de causas, puramente mecanicista. Mas a que género de historicismo se dirige a crítica benjaminiana? É sobretudo o sentido comum de historicismo que forma o objecto de tal crítica a perspectiva de Heussi, ou seja, o reducionismo e o evolucionismo. O que Benjamin critica é o historischer Sinn (ou o historicismo conservador) mediante o culto das "ideias históricas", nascido precisamente no contexto do historicismo. Esta problemática ganhou enorme importância durante a crise da Primeira Guerra (entre 1914-1918), mas os sinais desse forte impulso fizeram-se notar antes. E a reacção ao historicismo nasce, precisamente, no espírito da juventude, que radicaliza as suas posições, relativamente à filosofia da história. O impacto da segunda Consideração Intempestiva de Nietzsche também se faz sentir, no pensamento destes jovens. A crítica de Benjamin do historischer Sinn (BENJAMIN W. , 1974, 56-57), evoca, tanto no tom, quanto na argumentação, o texto de Nietszche.

A crítica do historisher Sinn, da mesma forma que a crítica sobre a pobreza cultural e a experiência do homem moderno, tem a sua origem num ideal romântico da cultura e faz-se acompanhar de uma metafísica do génio e da arte, da criação - que está presente, sobretudo, no primeiro Nietzsche (GW, I, 311). Na verdade, a juventude idealizada por Benjamin poderia ser 
reconhecida nas propostas nietszchianas ${ }^{1}$ contra os "filisteus" da cultura. E no texto do jovem Benjamin a densidade e profundidade da crítica nietzschiana do historischer Sinn desaparece, em proveito de um elemento projectivo, o messianismo, e de um idealismo que se liga à cultura e à pedagogia, sob o espírito objectivo de Wynecken, optando decisivamente por uma filosofia da história de orientação metafísica.

$\mathrm{Na}$ filosofia da história delineada pelo jovem Benjamin, o que define e estrutura o horizonte de sentido não são as épocas nem as finalidades da concepção historicista, mas sim o desenvolvimento "cultural-espiritual" da humanidade (BENJAMIN W. , 1974, 13-14), que tenta superar o relativismo e a crise dos valores, reflectindo sobre o modo como ela decepara a esperança da sua juventude e tentando restaura-la. É, sobretudo, no seu texto $A$ Vida dos Estudantes que melhor se reflecte a sua própria experiência e onde melhor se compreende a sua perspectiva da história - tomando, obviamente, a primeira fase da sua obra e das linhas de pensamento que o orientavam. Já na carta que Benjamin escreve a Carla Seligson, datada de 4 de Agosto de 1913 (BENJAMIN W. , Briefe I, 1993, 85-90), se anunciam os motivos que antecipam a filosofia da última fase de Benjamin, isto é, uma visão metafísica da história que se opõe ao historicismo e a crítica ao historischer Sinn. Nessa carta, a relação com a visão metafísica da história apresenta-se à luz da relação do homem com a comunidade e com a moralidade. Se estabelecermos uma relação dessa carta com o texto $A$ vida dos Estudantes, podemos, ainda, compreender melhor como Benjamin já antecipava claramente essa visão messiânica ${ }^{2}$ de que fala.

Na verdade, Benjamin representa já o "progresso" como uma forma da temporalidade mecânica e vazia, incoerente ${ }^{3}$. Nesse sentido, Benjamin colocase no coração da problemática pós-hegeliana. Se, por um lado, recusa o

1 Contra esses filisteus, opõe o ideal da cultura e da criação. Na primeira Consideração Intempestiva, o modelo do filisteu é David Strauss, crítico de Schopenhauer. Na oposição deste filisteu surge $o$ artista criador como o novo modelo.

2 G.S., II, 1, p. 75. Relembro o excerto em que ele afirma: "A tarefa histórica é a de dar forma absoluta, em toda a pureza, ao estado imanente da perfeição, de a tornar visível e de a fazer triunfar no presente. (...) Ela não é captável senão na sua estrutura metafísica, como o reino messiânico."

3 G.S., II, 1, p. 75: "A uma tal concepção (a do progresso) correspondem a incoerência, a imprecisão e a falta de rigor das suas pretensões em relação ao presente."

Professora do Instituto de Arte, Design e Empresa (IADE - Lisboa). Doutora pela Universidade Nova de Lisboa. Portuguesa, residente em Lisboa - Portugal. Email: micantinho@gmail.com 
historicismo; por outro, estamos diante do apelo à "salvação da história". Face ao evolucionismo e à ideia da pura sucessão linear dos factos, característica da história vista à luz do progresso, o jovem Walter Benjamin opõe a imagem da utopia como um "estado bem determinado", que ele identifica no mesmo encadeamento lógico a este famoso Brennpunkt (ponto focal), em redor do qual toda a história parece recolher-se em estado de repouso:

\begin{abstract}
Aqui, ao contrário, como fizeram sempre os pensadores, apresentando as imagens utópicas, nós consideramos a história à luz de uma situação determinada que a resume como um ponto focal (G.S. II, 1, 75).
\end{abstract}

Este "ponto focal" representa o fechamento, o ponto de paragem do tempo, e o ponto de condensação de uma tendência utópica e messiânica. Neste sentido, a experiência histórica afasta-se do relativismo e tende para o cumprimento. E fala de um "estado final" em que os elementos não seriam identificados, segundo ele, numa "tendência informe de progresso". Ao invés, este "estado final" (Endzustand) é constituído numa outra ordem de sentido: "Os elementos do Estado final não jazem como uma tendência informe do progresso, no seio de cada presente, mas eles estão profundamente enterrados, como as criações e os pensamentos, em grande perigo (...) profundamente ancoradas em todo o presente"( BENJAMIN,G.S.II,1, 75). Estas "criações" e "pensamentos" a que se refere Benjamin, constituem uma espécie de constelação meta-histórica e messiânica que se contrapõe à visão da moderna teolologia progressista. Desenha-se aqui uma perspectiva que antecipa o texto benjaminiano de 1940, Sobre o Conceito de História.

O estado de perfeição ou o telos soberano e absoluto a que se refere Benjamin no seu texto de 1915, A Vida dos Estudantes, escapa totalmente a toda a forma de narração ou de descrição histórica dos factos. À dimensão da história pragmática e empírica, Benjamin opõe a visão da história, na sua estrutura metafísica, como "o reino messiânico ou a ideia francesa de revolução". A dimensão metafísica da história define também a passagem da esfera "teológica" à da política, no sentido da "pureza" e do ideal revolucionário da juventude da sua época.

Professora do Instituto de Arte, Design e Empresa (IADE - Lisboa). Doutora pela Universidade Nova de Lisboa. Portuguesa, residente em Lisboa - Portugal. Email: micantinho@gmail.com 
Porém, esta "esperança messiânica", marcada por uma desformalização do tempo que já se encontrava presente em Franz Rosenzweig, aparece em Benjamin, à luz da teologia e da redenção teológica, exprimindo uma "esperança política" na ideia de uma restituição da justiça e de uma revolução, isto é, como uma "esperança ética" (BENJAMIN W. Gesammelte Schriften I, $1972,695)$ a que deve submeter-se indiscutivelmente o historiador. Para Benjamin, o passado, o presente e o futuro não são, assim, segmentos sucessivos sobre uma linha contínua, mas representam, antes, estados peculiares de consciência histórica. Orientada inequivocamente pelo desejo de "salvar a memória dos esquecidos" da história e dos "vencidos" e repondo a justiça do passado. A este ensejo de repor a justiça encontra-se sempre subjacente a ideia de redenção (erlösung). Tanto Jacques Derrida, na sua obra Marx \& Sons, quanto Gérard Bensussan, em Le Temps Messianique, frisam esta dimensão política e ética como fundamental face a uma interpretação teológica que é feita por alguns comentadores benjaminianos. A ideia de um "messianismo sem messias" como uma categoria da teologia judaica secularizada e aplicada à esfera da história, tem sido a interpretação mais forte do messianismo benjaminiano.

Desde os seus primeiros escritos, durante o seu período designado por muitos comentadores como o "primeiro Benjamin", como A Vida dos Estudantes (2015) Sobre a Linguagem em Geral e sobre a Linguagem humana (1916), passando pela sua tese de doutoramento, O Programa da Filosofia Vindoura (1917), O Conceito de Crítica de Arte no Romantismo Alemão (a sua tese de doutoramento, realizada entre 1919 e 1921) e A Tarefa do Tradutor (um texto que virá mais tarde, aquando da sua tradução de Baudelaire, mas que integra a sua concepção da Língua Pura na teoria da tradução), Benjamin auscultou a respiração que se ocultava nesses textos que ele tomou para si, nomeadamente no texto bíblico do Génesis e ainda a passagem bíblica sobre a Torre de Babel.

Latentes estão também, como um subsolo da sua teoria, as correntes da mística cabalística que Benjamin conheceu através de Scholem $^{4}$ e da leitura de

\footnotetext{
${ }^{4}$ Cf. Walter benjamin, Briefe, II, Suhrkamp verlag, Frankfurt am Main, 1966, carta de Benjamin a Scholem, datada de Junho de 1917, onde o autor fala com entusiasmo desses 
Joseph Molitor (Philosophie der Geschichte oder über die Tradition) e de Franz von Baader. Por outro lado, não se pode menosprezar a presença de pensadores como Wilhelm von Humboldt, Georg von Hamann, Jacob Böhme e do próprio ideal da língua universal de Leibniz ${ }^{5}$, que percorreram de forma intensa e vital todo o pensamento da linguagem até aos nossos dias. Nesses textos sobre a linguagem, Walter Benjamin bebeu profundamente e foram precisamente as suas vozes que conformaram uma visão judaica e messiânica da linguagem, isto é, a de uma perspectiva mágica daquela e que será amplamente abordada posteriormente - que se apresenta de forma muito explícita no primeiro texto, A Origem da Linguagem em Geral e da Linguagem humana ${ }^{6}$.

Para Benjamin há uma relação inequívoca entre a concepção da linguagem, como ele a entende, e a da Língua pura [reine Sprache] e messiânica, que aparece, não apenas no texto sobre a Linguagem, mas também e com particular importância no texto $A$ Tarefa do Tradutor (Die Aufgabe des Übersetzers). Tal como Mallarmé já o havia pensado, também Benjamin funda a sua metafísica da tradução sobre o conceito de uma "língua universal" e que é "a ideia da prosa", concepção que bebe no Pré-Romantismo.

A tradução é, assim, desse ponto de vista, para Walter Benjamin, possível e impossível, em simultâneo e segundo uma dialéctica paradoxal e íntima ao próprio raciocínio esotérico, pois todas as línguas conhecidas não são senão fragmentos cujas raízes se encontram na Língua pura, numa analogia que o próprio Benjamin estabelece com a Shekinah, no texto da tradução. No texto da tradução é a chegada à Língua Pura que se apresenta como o movimento de todas as línguas e a tarefa do tradutor é, na sua

dois autores cabalísticos que são, precisamente, Molitor (Philosophie der Geschichte oder über die Tradition oder über die Tradition) e Franz von Baader. Molitor foi-Ihe apresentado pelo entusiasta Scholem relativamente às suas leituras da mística judaica e da cabala. CF. Briefe, I, 136-139.

5 Cf. a notável obra de PETER FenVES, Arresting Language: from Leibniz to Benjamin, Stanford University Press, Stanford, 2001, que analisa a influência do ideal da língua universal de Leibniz, bem como as influências do romantismo e do idealismo alemão. Cf. também a obra de ANTOINe Berman, L'épreuve à l'étranger, Gallimard, Paris, 1984.

6 Cf. a carta que Walter Benjamin redige a Martin Buber, onde explicita esta "magia" da linguagem, em Junho de 1916, WALTER BENJAMIN, Briefe, I, p. 126. Cito, ainda, a este respeito os interessantes estudos de Winfried Menninghaus, especialmente o indispensável Walter Benjamins Theorie der Sprachmagie, suhrkamp Verlag, Frankfurt am Main, 1995, onde o autor aborda a questão da influência da cabala e dos autores místicos nesta concepção da magia da linguagem.

Professora do Instituto de Arte, Design e Empresa (IADE - Lisboa). Doutora pela Universidade Nova de Lisboa. Portuguesa, residente em Lisboa - Portugal. Email: micantinho@gmail.com 
natureza, uma tarefa messiânica, pois ela conduz a um ideal de pureza que encontramos no primeiro romantismo, guiado pela ideia de sobriedade do romantismo e idealismo alemães. Além da herança de Goethe, fundamental na formação de Benjamin, é de ressaltar a importância de Schlegel, de Novalis e de Schleiermacher como autores que o alimentaram durante a sua juventude ${ }^{7}$. É menos importante saber, no entanto, que esses autores contribuíram para o seu pensamento do que tentar determinar o modo como o pensamento benjaminiano incorporou essas teorias e lhes deu uma inimitável configuração, pela sua originalidade e, estudiosos e comentadores.

Numa carta que escreve a Scholem, datada de Junho de 1917, um ano após a redacção do seu texto sobre a linguagem, Sobre a Linguagem em Geral e sobre a Linguagem humana, Benjamin já traçara claramente o seu objectivo, deixando cair a leitura de Kant e a sua ideia da dissertação sobre "A tarefa Infinita em Kant". Os detalhes minuciosos dessa carta são preciosos porque nos indicam dois aspectos; por um lado, ela indicia a nova direcção do interesse e do trabalho do jovem Benjamin, por outro, permite desvendar os motivos pelos quais Kant não o interessava mais. A persistência benjaminiana em perseguir o rastro de um pensamento religioso e messiânico, em tentar definir uma tarefa messiânica que se imponha como uma das ideias fundamentais do seu pensamento.

Quando Benjamin afirma que "O ponto central do Primeiro Romantismo é a religião e a história-Das Zentrum der Frühromantik ist: Religion und Geschichte" (Briefe 1, 138), compreendemos claramente que o que o que lhe interessa é essa íntima relação entre os dois campos, o que abre o espaço para uma nova compreensão da história, insuflada pela força da religião, tal como o havia defendido Schlegel, nos seus textos. A ideia schlegeliana

7 A sua primeira obra com carácter sistemático foi precisamente WALTER BENJAMIN, Der Begriff der Kunstkritik in der deutschen Romantik, onde Benjamin se confronta com o pensamento romântico. Já nessa época, o rigor científico impede-lhe que se dedique ao messianismo que ele considera como a força secreta do romantismo, de acordo com uma carta redigida pelo próprio a Ernst Schoen. Cf. carta de 7 de Abril de 1919, in WALTER BENJAMIN, Briefe, I, p. 208: "Meti um ponto final há alguns dias na confusão da minha tese. Ei-la transformada naquilo que ela deveria ser: uma abertura sobre a verdadeira natureza do romantismo, neglicenciada por todo o lado na literatura, mas esta indicação não é senão indirecta: eu não podia abordar o messianismo, o coração do romantismo - não tratei senão da concepção da arte - nem mais nada do que me é presente ao mais elevado ponto sem me interditar a possibilidade da atitude científica (...)".

Professora do Instituto de Arte, Design e Empresa (IADE - Lisboa). Doutora pela Universidade Nova de Lisboa. Portuguesa, residente em Lisboa - Portugal. Email: micantinho@gmail.com 
(Lacoue-Labarthe, 1978, pp. 216-222) de uma relação do homem com o infinito e com o seu próprio destino histórico é definida a partir do sentimento religioso (ideia 81$)^{8}$. Ao mesmo tempo, Schlegel define essa relação do homem com o infinito como a sua própria plenitude e liberdade. Não é ao homem, enquanto indivíduo, que cabe essa tarefa de religação, mas ao indivíduo tomado como humanidade, pois o homem só é "humano" quando penetrado dessa humanidade (ideia 65). Esta ideia remete-nos inequivocamente para a ideia de uma "tarefa" a cumprir, insuflada pelo espírito religioso do homem, como igualmente contribuíram de forma decisiva para a redacção do seu texto Sobre o Conceito de Crítica de Arte no Romantismo.

$\mathrm{Na}$ teoria da linguagem benjaminiana, partimos de um princípio: se a linguagem é uma matriz essencial, "essência íntima do mundo (...) de onde surgiu a palavra", (Briefe 1,197), então aqueles que a consideram como uma colecção meramente arbitrária de signos ${ }^{9}$, isto é, como pura convenção, não compreendem a sua verdadeira natureza. Uma vez desaparecida a crença nos símbolos no mundo moderno, Benjamin acreditava que a tarefa da filosofia (opondo-a à ciência) era a de "restabelecer, na sua primazia, mediante a apresentação [Darstellung], o carácter simbólico da palavra, na qual a ideia chega ao seu autoconhecimento, que é o oposto de toda a comunicação orientada para o exterior." ${ }^{10}$ Assim, é nos nomes que se concentra toda a potência simbólica ${ }^{11}$ da linguagem, pois são eles que contêm, "a um nível

8 PH. LACOUE-LABARTHE, J.L. NANCY, L'Absolu Littéraire, Théorie de la littérature du romantisme allemand, tradução francesa de Schlegel, p. 214: "Toda a relação do homem ao infinito é religião, quero dizer toda a relação do homem, na plenitude inteira da sua humanidade. Quando o matemático calcula o infinitamente grande, isto não é certamente a religião. Pensado nesta plenitude, o infinito é a divindade.

9 Esta ideia, segundo a qual a linguagem é mais um corpo de símbolos do que um sistema de signos arbitrários, em que o homem se serve da linguagem para dar forma e configurar as percepções dos sentidos, dá conta de uma afinidade entre os neo-kantianos e Benjamin especialmente Cassirer, A Filosofia das formas simbólicas). Ainda que não tenhamos a certeza que Benjamin tenha lido Cassirer, no entanto é sabido que foi aluno de Rickert e teve conhecimento dessa teoria.

10 G.S., I, 1, A Origem do Drama Barroco Alemão, pp. 216, 217. Ressalte-se que este texto foi redigido entre 1924-1926, vários anos depois do texto benjaminiano sobre a linguagem, mas onde podemos verificar o desenvolvimento de conceitos que aparecem no texto sobre a linguagem, nomeadamente o nome e o carácter simbólico da linguagem.

${ }^{11}$ Quase no final do texto Sobre a Linguagem em Geral e sobre a Linguagem Humana, G.S., II, 1 , p. 156, Benjamin diz, sobre a função simbólica da linguagem algo que retomaremos constantemente: "A linguagem não é, com efeito, em todos os casos, apenas comunicação do comunicável, mas ao mesmo tempo símbolo do não-comunicável. Este lado simbólico da

Professora do Instituto de Arte, Design e Empresa (IADE - Lisboa). Doutora pela Universidade Nova de Lisboa. Portuguesa, residente em Lisboa - Portugal. Email: micantinho@gmail.com 
incomparável do ser a mais íntima essência da própria linguagem" (BENJAMIN W. , 1974, 144).

A linguagem é expressão de uma essência espiritual e esta é comunicada na própria linguagem (BENJAMIN W. , 1974, 144). Deste modo é "evidente desde o princípio que a essência espiritual que se comunica na linguagem não é a própria linguagem, mas qualquer coisa que convém distinguir." Mas o "que comunica a linguagem? Ela comunica a essência espiritual que the corresponde. É fundamental saber que esta essência espiritual se comunica na linguagem e não através dela. Não existe, então, nenhum locutor de linguagens se se designa assim aquele que se comunica através destas linguagens." (Ibidem, 142). Numa linha de pensamento que se vai desenvolvendo, Benjamin afirma que "toda a linguagem se comunica a si própria." ${ }^{12}$ Esta afirmação corrobora a ideia de que partimos inicialmente, a da recusa da comunicação da linguagem para o exterior. É nesta acepção que ela é, no "sentido mais puro do termo, o «» da comunicação." (Idem). E o que é próprio deste carácter de «» é precisamente a sua imediatez, isto é, a sua magia. E se essa magia também Ihe advém do "seu carácter infinito", aquilo que é comunicado na linguagem "não pode ser limitado ou medido de fora". Não são os conteúdos verbais que definem a linguagem, mas sim a "sua essência linguística" (BENJAMIN W. , 1974, 143). Vemos, aqui, claramente, a recusa da teoria linguística do signo e, em oposição a estas, Benjamin vai elaborar uma concepção metafísica da linguagem. As palavras dele são claras a esse respeito, quando afirma: "Antes de proceder à resposta a esta questão, é preciso, mais uma vez, pôr isto à prova: como se comunica o ser humano? Há uma diferença profunda a fazer, uma alternativa a colocar, diante da qual a opinião essencialmente errada acerca da linguagem seguramente se trai. Será que o ser humano comunica a sua essência espiritual mediante os nomes [durch die Namen] que ele dá às coisas, ou será em eles? [In die Namen] [sublinhado do autor]." (BENJAMIN W. , 1974, 143)

Aqui vemos a contraposição clara entre as duas concepções. O comunicar através de e o comunicar nos nomes. A primeira concepção, que

\footnotetext{
linguagem depende da sua relação com o sinal, mas expande-se, também, sob uma certa relação, por exemplo pelo nome e pelo juízo."

12 "Jede Sprache teilt sich selbst mit".

Professora do Instituto de Arte, Design e Empresa (IADE - Lisboa). Doutora pela Universidade Nova de Lisboa. Portuguesa, residente em Lisboa - Portugal. Email: micantinho@gmail.com
} 
implica uma exterioridade do homem relativamente à linguagem e ao nome, é recusada: "No paradoxo desta formulação interrogativa está contida a sua resposta. Quem acreditar que o ser humano comunica a sua essência espiritual mediante dos nomes [durch die Namen], esse não pode aceitar, por sua vez, que a sua essência espiritual seja o que ele comunica." (p. 144). Se a primeira concepção designa uma concepção burguesa da linguagem [die bürgerliche Auffassung der Sprache], a recusa de Benjamin visa essencialmente o seu carácter "insustentável e vazio" (Idem). Esta perspectiva burguesa "consiste em dizer: o meio da comunicação é a palavra, o seu objecto é a coisa, o seu destinatário é o homem". Enquanto isso, a concepção metafísica, que Benjamin reclama, é "aquela que não conhece nem meio nem objecto, nem destinatário da comunicação. Ela diz: "no nome, a essência espiritual do homem comunicase a Deus." [In Namen teilt das geistige Wesen des Menschen sich Gott mit] [sublinhado do autor]. É o nome que dá à linguagem o seu carácter divino, pois a linguagem foi atribuída ao homem como um dom (Gabe), que the permite nomear e reconhecer as outras criaturas como criadas por Deus. O nome arranca aquilo que nomeia à sua mudez, reconhecendo a coisa como criatura, neste sentido, se o homem nomeia as coisas, está também a comunicar a própria essência espiritual a Deus: como aquele que nomeia. Não procura um destinatário nem um meio de comunicar, diz-se a si próprio, na sua essência espiritual, a Deus, nomeando. Esta é a esfera da linguagem pura (Ibidem, 144) e imediata que, nomeando, se diz a si própria àquele que the concedeu o dom da linguagem. "O nome", diz Benjamin, "é a súmula desta totalidade intensiva da linguagem, enquanto totalidade da essência espiritual do homem" (Ibidem, 144) e, neste sentido, é enquanto totalidade que ele se "comunica a Deus". A criação divina não conhece o seu acabamento sem a nomeação humana, por essa razão, quando ele nomeia as coisas, enquanto senhor da natureza, comunica-se, em os nomes a Deus, na sua própria essência espiritual. Só por ele, ou melhor, nele, a linguagem fala, no nome. E comunica-se a quem? A Deus. Desta forma, o homem não só é o locutor da linguagem, como "é o único locutor da linguagem".

Esta concepção da linguagem nomeadora, ou seja, de uma linguagem pura, jamais será abandonada por Benjamin, como se verá. Neste sentido, a 
ideia de uma "teoria dos nomes", seja qual for a origem, é a matriz essencial do pensamento da linguagem benjaminiana. E é nele, no nome, que se concentra, ao mais alto nível, a essência íntima da linguagem, o nome tomado como "aquilo pelo qual nada se comunica e no qual a linguagem se comunica a si própria e de forma absoluta" (BENJAMIN W. , 1974,144). Garantia da "essência espiritual" do homem, garantia, igualmente, de que é "nele que a essência espiritual do homem se comunica a Deus"13, é precisamente no nome, que o distingue de todas as outras criaturas. Aqui ressoa o eco das palavras de Hamann e isso, particularmente na questão da linguagem enquanto Revelação. Não é por acaso que Benjamin cita Hamann no ensaio Sobre a Linguagem em Geral e sobre a Linguagem Humana:"Linguagem, a mãe da razão e Revelação, o seu A e $\Omega$ " (BENJAMIN W. , 1974, 147). É a "equiparação da essência espiritual e linguística que nos conduz e nos remete para a questão da Revelação. Benjamin estabelece uma distinção entre a linguagem humana e a linguagem das coisas (Ibidem,146). Se no homem, pela sua capacidade nomeadora, a linguagem conhece a sua perfeição espiritual e a máxima intensidade, nas próprias coisas a linguagem não se expressa de modo perfeito. Elas são mudas por lhes ser negado o "puro princípio formal da linguagem - o som." (Ibidem). Por isso, elas só podem comunicar umas com as outras de forma material, estabelecendo, entre elas, uma comunidade material. No entanto, esta comunidade é, ainda, mágica, pela razão de que ela é imediata e infinita. E não é comparável à linguagem humana pela razão de ser material, enquanto a linguagem humana é "imaterial e puramente espiritual". 0 nome é a possibilidade, oferecida por Deus como um dom, que o eleva acima da natureza, de arrancar as coisas à sua mudez. Tal é a magia da linguagem. As coisas "falam-nos", dizem-nos, imediata e infinitamente do que elas "nos" falam, elas "dizem-se" imediatamente no nome, em toda a sua intensidade.

A nomeação é, assim, a tradução da linguagem das coisas - linguagem material - na linguagem do ser humano. E é, precisamente nela que é preciso encontrar o fundamento da tradução, isto é, "é necessário fundar o conceito de tradução no estrato mais profundo da teoria da linguagem" (BENJAMIN W. , $1974,151)$. É nesta passagem do texto que encontramos um elo de ligação

${ }^{13}$ Idem, p. 144: "im Namen teilt das geistige Wesen des Menschen sich Gott mit."

Professora do Instituto de Arte, Design e Empresa (IADE - Lisboa). Doutora pela Universidade Nova de Lisboa. Portuguesa, residente em Lisboa - Portugal. Email: micantinho@gmail.com 
entre a teoria da nomeação e a da tradução, o que nos permite concluir que a tradução transporta consigo o traço dos nomes. Se a traduzibilidade das linguagens umas nas outras é possível é porque ela se constitui como "o transporte de uma linguagem na outra, através de um continnum de transfigurações" (Ibidem) e de metamorfoses que trazem em si os nomes como vestígios da linguagem nomeadora. Nessa medida, é à tradução que cabe redescobrir o poder nomeador da linguagem, pela apresentação, como veremos no capítulo relativo à tradução.

A nomeação é, não só a tradução da mudez das coisas em som humano, como é, em si, o resgate das próprias coisas, elevando-as à condição da linguagem humana. O nome, neste sentido, "redime" a própria coisa por lhe conceder um estatuto mais perfeito, por um lado, e, por outro, por the acrescentar algo: o conhecimento. E a objectividade da tradução das coisas na linguagem nomeadora é garantida por Deus, não pelo homem. É nesta objectividade divina, portanto, que se funda o conceito de tradução, como também a própria traduzibilidade. Deste modo (e apesar de o texto $A$ Tarefa do tradutor ser redigido anos mais tarde, em 1923), podemos concluir que, já no texto Sobre a Linguagem em Geral e sobre a Linguagem Humana, Benjamin se preocupava com as questões da legitimidade e do princípio da tradução e preparava, neste texto, a sua teoria da linguagem para servir de fundamento a uma teoria da tradução, essa sim, que aparece como uma verdadeira tarefa messiânica e que conduz à língua pura e messiânica. Mas se a expressão de tarefa messiânica não aparece, no texto Sobre a Linguagem em Geral e sobre a Linguagem Humana, como claramente desenvolvido, a teoria da nomeação (enquanto fundamento da linguagem) contém em si o germe de uma tarefa messiânica, que cabe à tarefa da tradução (re)descobrir, restaurando o poder simbólico da linguagem, o "índice secreto e messiânico" que ela traz em si. É esse o significado do último parágrafo do texto de Sobre a Linguagem em Geral e sobre a Linguagem Humana, pois quando Benjamin fala no residuum da palavra criadora de Deus (BENJAMIN W. , Briefe I, 1993, 157) que atravessa toda a natureza e que o nome dá voz e, enquanto nomeia, salva-a no conhecimento, está certamente a falar no sopro de uma língua pura e divina 
que atravessa toda a natureza e que se diz no homem, no nome, de forma imediata e mágica.

A comparação benjaminiana da linguagem da natureza a uma "senha secreta que cada sentinela transmite à seguinte na sua própria linguagem" alude precisamente a esse índice messiânico que se oculta na linguagem, mas mais precisamente, na linguagem nomeadora e "originária". E se "cada linguagem mais elevada é a tradução da inferior", então essa aragem messiânica, sibilina e vigilante, perpassa toda a linguagem, cabendo à tradução a redescoberta do poder messiânico e simbólico da palavra. Benjamin fala na "derradeira claridade" em que "se descobre a palavra de Deus", sendo que esta é a "unidade deste movimento da linguagem" (Ibidem). Essa unidade, convém que se diga, é a unidade da língua pura, aquela que é o alvo de toda a tradução. Isto é, a língua messiânica, que só a história das línguas deixa entrever, nas metamorfoses operadas pela tradução.

Retornemos à ideia que nos serviu aqui de mote: a de que existe em Walter Benjamin um fio de Ariadne que nos conduz, ou seja, a ideia de que a tarefa do historiador é aquela que permite (re)descobrir a "frágil força messiânica" ou o índice messiânico que os nossos antecedentes nos legaram. E já não é o jovem Benjamin quem diz isto, mas o último Benjamin, o homem amadurecido e atormentado que escreveu em jeito de testamento Sobre o Conceito de História. É na tese II que ele o afirma, reafirmando ou confirmando a ideia de que trazia consigo esta tarefa por cumprir e que é a tarefa do próprio anjo da história, reclamando a justiça para os vencidos, lutando por lhes dar, não só um rosto, mas também um nome. Um nome que perdure na memória e na tradição, que os salve. $E$ isso é a tarefa da linguagem, não a da comunicação, instrumentalizada, mas a da própria manifestação da história. Muitos não quiseram ou não souberam perdoar-lhe a contradição, que nada tinha a ver com a teologia, mas com um desejo de fazer justiça, profundamente ético, que contém a vibração de uma actualidade integral e, "de todos os lados, aberta. Só nela existe a história universal". Porque a história não pertence apenas aos vencedores. 


\section{REFERÊNCIAS}

AGAMBEN, G. (1983). Langue et Histoire. Catégories historiques et catégories linguistiques dans la pensée de Walter Benjamin. Dans H. Huisman, Walter Benjamin et Paris. Paris: Éditions du Cerf.

AGAMBEN, G. (1990). La Communauté qui vient: Théorie de la singularité quelconque. (M. Raiola, Trad.) Paris: Seuil.

Amon Pinho, M. J. (2015). Walter Benjamin: Novos Estudos e Perspectivas . São Paulo: Editora Hedra, Edufu.

BENJAMIN, W. (1972). Gesammelte Schriften I. Frankfurt am Main: Suhrkamp Verlag.

Benjamin, W. (1972). Gesammelte Schriften IV. Frankfurt am Main: Suhrkamp Verlag.

Benjamin, W. (1972). Gesammelte Schriften VI. Frankfurt am Main: Suhrkamp Verlag.

Benjamin, W. (1972). Gesammelte Schriften VII. Frankfurt am Main: Suhrkamp Verlag.

BENJAMIN, W. (1974). Gesammelte Schriften II (Vol. II). Frankfurt am Main: Suhrkamp Verlag.

BENJAMIN, W. (1982). Gesammelte Schriften V. Frankfurt am Main: Suhrkamp Verlag.

BENJAMIN, W. (1993). Briefe I. Frankfurt am Main: Suhrkamp Verlag.

BENJAMIN, W. (1993). Briefe II. Frankfurt am Main: Suhrkamp Verlag.

Benjamin, W. (2010). O Anjo da História. (J. Barrento, Trad.) Lisboa: Assírio \& Alvim.

BENJAMIN, W. (2010). O Anjo da História. (J. Barrento, Trad.) Lisboa: Assírio \& Alvim.

BERMAN, A. (1995). L'épreuve de l'Étranger. Paris: Flammarion.

BERMAN, A. (2008). L'Âge de la Traduction. Paris: Presses Universitaires de Vincennes.

FENVES, P. (2001). Arresting Language: From Leibniz to Benjamin. Stanford: Stanford University Press.

HAMANN, G. v. (2014). Hamann'S Schriften: Th. Metakritik Über Den Purismum Der Reinen Vernunft. Nabu Press. 
Lacoue-Labarthe, J. N. (1978). L'Absolut Littéraire, Théorie de la Littérature du Romantisme Allemand. Paris: Seuil.

Lavelle, P. (2008). Religion et Histoire. Paris : Éditions du Cerf.

Löwy, M. (1988). Rédemption et Utopie. Le Judaïsme Libertaire en Europe Centrale. Une étude d'Affinité élective. Paris: PUF.

Löwy, M. (1989). Redenção e Utopia: o judaísmo libertário na Europa central. São Paulo: Companhia das Letras.

LÖWY, M. (2001). L'Avertissement de l'Incendie. Paris: PUF.

MENNINGHAUS, W. (1980). Walter Benjamins Theorie der Sprachemagie. Frankfurt: Suhrkamp Verlag.

Nietzsche, F. (2011). Escritos Sobre História. Rio/S.Paulo: Editora PucRio/Edições Loyola. 